CONCLUSION

In summary, in this study population after follow up of an average of 6.6 years for the men with a vasectomy, we found no evidence to support the hypothesis that vasectomy leads to an increase in the incidence of the various diseases studied. In particular, we found no evidence of an increase in the incidence of testicular cancer.

1 Lepow IH, Crozier R, eds. Vasectomy: immunologic and pathophysiologic effects in animals and in man. New York: Academic Press, 1979.

Linnet L. Clinical immunglogy of vasectomy and vasovasostomy. Urology 1983:22:101-14.

3 Alexander NJ, Clarkson TB. Vasectomy increases the severity of diet-induced atherosclerosis in Macaca fascicularis. Science 1978;201:538-41.

4 Clarkson TB, Alexander NJ. Long-term vasectomy effects on the occurrence and extent of atherosclerosis in rhesus monkeys. F Clin Invest 1980;65:

5 Goldacre MJ, Holford TR, Vessey MP. Cardiovascular disease and vasectomy: findings from two epidemiologic studies. N Engl f Med 1983;308: 805-8

6 Tang Guang-Hua, Zong Yu Hui, Ma Yue-Min, Luo Lin, Cui Kai, Luo Jian, $e t a l$. Vasectomy and health: cardiovascular and other diseases following vasectomy in Sichuan Province, People's Republic of China. Int $\mathcal{f}$ Epidemio 1988;17:608-17.

7 I-Cheng Chi, Ung Ring Ko, Wilkens LR, Chang HK, Nam JJ. Vasectomy and non-fatal acute myocardial infarction: a hospital-based case-control study in Seoul, Korea. Int f E pidemiol 1990;19:32-41.

8 Walker AM, Jick H, Hunter JR, Danford A, Rothman KJ. Hospitalization rates in vasectomized men. FAMA 1981;245:2315-7.

9 Massey FJ, Bernstein GS, O'Fallon WM, Schuman LM, Coulson AH, Cozier $\mathrm{R}$, et al. Vasectomy and health: results from a large cohort study. JAMA 1984;252:1023-9.

10 Perrin EB, Woods JS, Namekata T, Yagi J, Bruce RA, Hofer V. Long-term effect of vasectomy on coronary heart disease. Am $\mathcal{f}$ Public Health 1984; $74: 128-32$

11 Strader CH, Weiss NS, Daling JR. Vasectomy and the incidence of testicular cancer. Am f Epidemiol 1988;128:56-63.

12 Thornhill JA, Conroy RM, Kelly DG, Walsh A, Fennelly JJ, Fitzpatrick JM
An evaluation of predisposing factors for testis cancer in Ireland. Eur Urol 1988:14:429-33.

13 Cale ARJ, Farouk M, Prescott RJ, Wallace IWJ. Does vasectomy accelerate testicular tumour? Importance of testicular examinations before and after vasectomy. $B M \mathcal{A}$ 1990;300:370.

14 McDonald SM. Vasectomy and the human testis. BM 1990;301:618-9.

5 Rosenberg L, Palmer JR, Zauber AG, Warshauer ME, Stolley PD, Shapiro S. Vasectomy and the risk of prostate cancer. Am $\mathcal{F}$ Epidemiol 1990;132:1051-5. 6 Mettlin G, Natarajan N, Huben R. Vasectomy and prostate cancer risk. Am J Epidemiol 1990;132:1056-61.

17 Acheson ED. Medical record linkage. London: Oxford University Press, 1967. 18 Gill LE, Baldwin JA. Methods and technology of record linkage: some practical considerations. In: Baldwin JA, Acheson ED, Graham WJ, eds. Textbook of medical record linkage. Oxford: Oxford University Press, 1987:39-54.

19 Goldacre MJ. Collection, analysis and dissemination of vital and health statistics. In: Smith A, ed. Recent advances in community medicine. No 3. Edistics. In: Smith A, ed. Recent adoanses in co

20 Sellar C, Goldacre MJ, Hawton K. Reliability of routine hospital data on poisoning as measures of deliberate self-poisoning. $\mathcal{F}$ Epidemiol Community Health 1990;44:313-5.

21 Seagroatt V, Tan HS, Goldacre M, Bulstrode C, Nugent I, Gill L. Elective total hip replacement: incidence, emergency readmission, and postoperative mortality. $B M F$ 1991;303:1431-5.

22 Harrell FE. The PHGLM procedure. In: SUGI supplemental library user's guide. Version 5. Cary, North Carolina: SAS Institute, 1986:437-66.

23 Muir C, Waterhouse J, Mack T, Powell J, Whelan S, eds. Cancer incidence in five continents. Vol 5. Lyons: International Agency for Research on Cancer, 1987:660-2.

24 Goldacre M, Vessey M, Clarke J, Heasman M. Record linkage study of morbidity following vasectomy. In: Lepow IH, Crozier R, eds. Vasectomy: immunologic and pathophysiologic effects in animals and man. New York: Academic Press, 1979:567-75.

25 Moss AR, Osmond D, Bacchetti P, Torti FM, Gurgin V. Hormonal risk factors in testicular cancer: a case-control study. Am J Epidemiol 1986;124: 39-52.

26 Swerdlow AJ, Huttley SRA, Smith PG. Testicular cancer and antecedent diseases. Br f Cancer 1987;55:97-103.

27 Sidney $S$. Vasectomy and the risk of prostatic cancer and benign prostatic hypertrophy. F Urol 1987;138:795-7.

28 Kronmal RA, Alderman E, Krieger JN, Killip T, Kennedy JW, Athearn MW. Vasectomy and urolithiasis. Lancet 1988;i:22-3.

(Accepled 3 fanuary 1992)

\title{
Melanoma in people aged 65 and over in Scotland, 1979-89
}

\author{
Pamela M McHenry, David J Hole, Rona M MacKie
}

University Department of Dermatology, Western Infirmary, Glasgow G11 6NT

Pamela M McHenry, MRCP, registrar

Rona M MacKie, FRCPATH, professor

Cancer Surveillance Unit, Ruchill Hospital, Glasgow

David J Hole, MSC, statistician

For and on behalf of the Scottish Melanoma Group.

Correspondence to: Dr McHenry.

\section{Abstract}

Objective-Detailed analysis of primary cutaneous melanoma first diagnosed in Scotland in patients aged 65 and over.

Design-Comparison of changing incidence, sex distribution, site, histogenetic type, tumour thickness, and prognosis of all primary cutaneous melanomas in patients aged 65 and over diagnosed in Scotland in the 11 years $1979-89$ with similar data for patients aged under 65 .

Setting-Data were obtained from the Scottish Melanoma Group's database, established in 1979, which aims to record detailed clinical, pathological, and surgical follow up details of all primary cutaneous melanomas registered in Scotland.

Patients-1430 patients (954 women, 476 men) aged 65 and over; comprising over a third of the 3903 patients with primary melanoma recorded for all age groups in Scotland during this period.

Results-The overall incidence of melanoma in patients aged 65 and over increased from $12 \cdot 2 / 100000$ in 1979 to $20 \cdot 7 / 100000$ in 1989 , with the greatest increase seen in older men, from $7 \cdot 8 / 100000$ in 1979 to $18 \cdot 0 / 100000$ in 1989 . The site most commonly affected was the face in both men and women (33\% of all tumours). The most common histogenetic type was superficial spreading melanoma. 526 patients $(37 \%)$ had melanomas with a tumour thickness of $3.5 \mathrm{~mm}$ or greater in the older age group, compared with 453 patients $(18 \%)$ in those aged under 65 . The highest proportion of thick tumours was seen in older men. Five year survival figures for 616 patients diagnosed between 1979 and 1984 were $88 \%, 66 \%$, and $47 \%$ for thin, intermediate, and thick tumours respectively. Overall five year survival for the older age group was $64 \%$ compared with $78 \%$ for the younger age group.

Conclusion-The increase in melanoma in the elderly and the high proportion of thick tumours, especially in men, require a specific educational programme for both primary and secondary prevention directed towards the older population.

\section{Introduction}

The incidence of cutaneous melanoma is rising steadily. Melanoma is a solid tumour that can affect al age groups, and the median age world wide at presentation is 48 years.' The most important prognostic factor in primary melanoma is the tumour thickness as measured microscopically from the granular layer of the overlying epidermis to the deepest underlying malignant melanoma cell. ${ }^{2}$ Recently several public education exercises have been aimed at secondary prevention of melanoma, particularly in younger people. Our impression in our pigmented lesion clinic in the west of Scotland was that younger members of the public were becoming better informed about melanoma and seeking advice earlier about thinner tumours, leading in turn to a better prognosis, but in the over $65 \mathrm{~s}$ many patients were still not aware of the signs of early melanoma. We also had the impression that older patients were not seeking medical treatment until their melanomas were relatively thick.

A current concept of melanoma in elderly people is that it is mainly of the lentigo maligna melanoma type and is a slowly growing non-aggressive tumour. This image was inconsistent with our own experience. For 
these reasons we carried out a detailed analysis of primary melanomas occurring in Scotland in those aged 65 and over.

\section{Patients and methods}

The Scottish Melanoma Group, established in 1979, aims to record detailed clinical, pathological, and surgical follow up details of all primary cutaneous melanomas registered in Scotland. Pathologists cooperate by completing a registration form for the Scottish Melanoma Group when they diagnose invasive melanoma (Clark level 2 or deeper). The Scottish Melanoma Group's records are compared annually with those of the cancer registry and discrepancies in both records are corrected.

Registration with the Scottish Melanoma Group covers both NHS and private hospitals in Scotland. Details of registrations supplied by the pathologist include the gross size of the excised specimen and lesion, site of the lesion, presence of ulceration, histogenetic type, Clark level, Breslow thickness, cell type, and completeness of excision. Additional features recorded include the presence or absence of vascular invasion, amount of lymphocytic infiltrate, and evidence of regression. The surgeon responsible for the primary management of the lesion supplies details of any diagnostic biopsy and of the definitive excision procedure. Thereafter follow up information is requested from the responsible physician at annual intervals.

We studied the changing incidence, sex distribution, site, histogenetic type, tumour thickness, and prognosis of all primary cutaneous melanomas registered in Scotland over the 11 year period 1979 to 1989 in patients aged 65 and over and compared our observations with those in patients aged under 65 years at the time of primary treatment for melanoma. Data on five year survival have been limited to patients diagnosed between 1979 and 1984, the year before the introduction of a public education programme in Scotland aimed at encouraging earlier referral of primary melanomas.

\section{STATISTICAL METHODS}

Incidence rates were standardised to the age distribution of persons in Scotland at the 1981 census. Trends over time were estimated by deriving the best fit linear regression of incidence against year. Probability values were derived from the significance of the steepness of the gradient of the regression equation.

The percentages of tumours with a Breslow thickness of $1.5 \mathrm{~mm}$ or greater before and after the introduction of the public education campaign were compared using a logistic regression model. ${ }^{3}$ This allowed adjustment to be made for variations in age, site, and histogenetic type over the period of the study.

The percentage of patients surviving five years was estimated by using life table techniques ${ }^{4}$ both for mortality from all causes and for deaths considered to be tumour related.

\section{Results}

In the period $1979-89,1430$ patients (954 women and 476 men) aged 65 years or over were registered in Scotland with primary cutaneous melanoma (table I), comprising over a third $(37 \%)$ of the 3903 primary melanomas recorded for all age groups in Scotland during this period. This represents an overall increase in age and sex adjusted incidence from $12 \cdot 2 / 100000$ in 1979 to $20 \cdot 7 / 100000$ in 1989 in those patients aged 65 and over. Figure 1 illustrates the increase in all age groups. The greatest increase, $131 \%$, is seen in older men, in whom over the 11 year period the incidence increased from $7 \cdot 8 / 100000$ to $18 \cdot 0 / 100000$.
In series looking at all age groups, the most common site of melanoma is the leg in women and the trunk in men. In our patients aged 65 and over, however, the face was the most common site in both men and women (table II). Of all primary melanomas in older men, 212 $(45 \%)$ were found in the head and neck area, with 334 melanomas $(35 \%)$ occurring in this region in older women. Lentigo maligna melanoma was the most common histogenetic type found in the head and neck area, accounting for $56 \%$ (306) of the melanomas. Nodular melanomas comprised 24\% (133) and superficial spreading melanoma $13 \%(70)$ of head and neck

TABLE I-Incidence of primary cutaneous melanoma in Scotland $1979-89$

\begin{tabular}{|c|c|c|c|c|}
\hline & \multicolumn{2}{|c|}{ Men } & \multicolumn{2}{|c|}{ Women } \\
\hline & $\begin{array}{c}\text { Age } \geqslant 65 \\
\text { No }(\text { rate })^{\star}\end{array}$ & $\begin{array}{c}\text { Age }<65 \\
\text { No }(\text { rate })^{\star}\end{array}$ & $\begin{array}{c}\text { Age } \geqslant 65 \\
\text { No }(\text { rate })^{\star}\end{array}$ & $\begin{array}{c}\text { Age }<65 \\
\text { No }(\text { rate })^{\star}\end{array}$ \\
\hline 1979 & $21(7 \cdot 8)$ & $60(2 \cdot 8)$ & $73(16 \cdot 5)$ & $103(4 \cdot 7)$ \\
\hline 1980 & $36(13 \cdot 2)$ & $47(2 \cdot 2)$ & $79(17 \cdot 6)$ & $104(4 \cdot 7)$ \\
\hline 1981 & $37(13 \cdot 3)$ & $49(2 \cdot 2)$ & $68(15 \cdot 2)$ & $97(4 \cdot 4)$ \\
\hline 1982 & $31(11 \cdot 1)$ & $59(2 \cdot 7)$ & $72(15 \cdot 8)$ & $119(5 \cdot 3)$ \\
\hline 1983 & $40(13.9)$ & $66(3 \cdot 0)$ & $77(17 \cdot 0)$ & $135(6 \cdot 0)$ \\
\hline 1984 & $39(13.9)$ & $76(3 \cdot 4)$ & $83(18 \cdot 6)$ & $141(6 \cdot 2)$ \\
\hline 1985 & $55(19 \cdot 7)$ & $95(4 \cdot 2)$ & $83(18 \cdot 1)$ & $183(8 \cdot 1)$ \\
\hline 1986 & $44(15 \cdot 5)$ & $93(4 \cdot 1)$ & $118(25 \cdot 2)$ & $179(8 \cdot 0)$ \\
\hline 1987 & $48(16 \cdot 4)$ & $91(4 \cdot 0)$ & $100(21 \cdot 4)$ & $156(6.9)$ \\
\hline 1988 & $70(23 \cdot 7)$ & $113(5 \cdot 0)$ & $92(19.5)$ & $202(9 \cdot 0)$ \\
\hline 1989 & $55(18.0)$ & $129(5 \cdot 7)$ & $109(23.4)$ & $176(7.9)$ \\
\hline Total & 476 & 878 & 954 & 1595 \\
\hline
\end{tabular}

*Age standardised rate/100000 (standardised to age distribution of 1981 Scottish population).

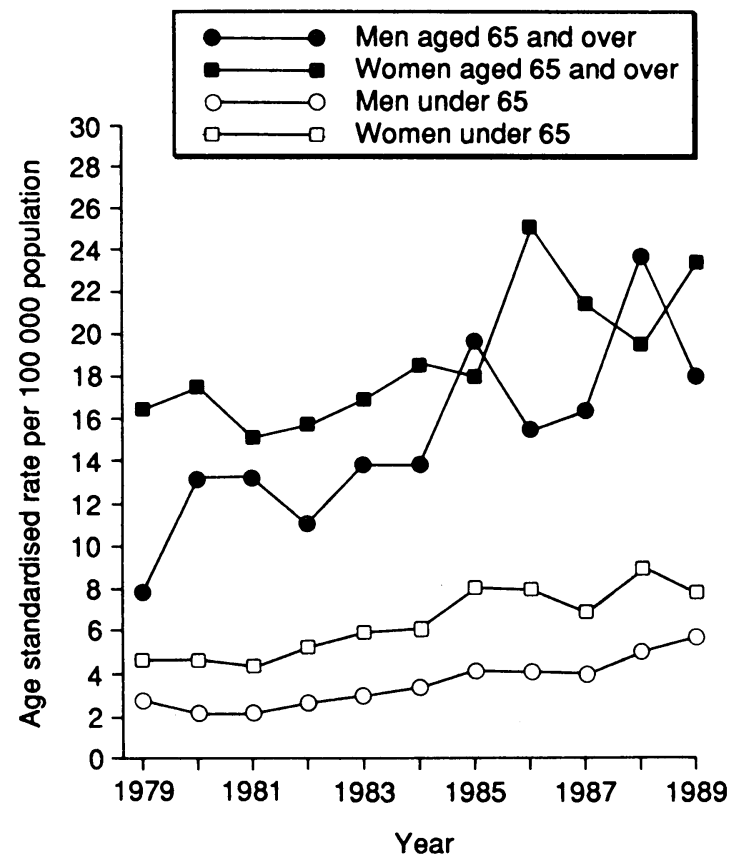

FIG 1-Incidence of melanoma in Scotland, 1979-89

TABLE II - Site of melanoma

\begin{tabular}{|c|c|c|c|c|}
\hline & \multicolumn{2}{|c|}{$\begin{array}{l}\text { No (\%) of men with } \\
\text { tumours }\end{array}$} & \multicolumn{2}{|c|}{$\begin{array}{l}\text { No (\%) of women with } \\
\text { tumours }\end{array}$} \\
\hline & Age $\geqslant 65$ & Age $<65$ & Age $\geqslant 65$ & Age $<65$ \\
\hline Face & $154(32 \cdot 7)$ & $67(7 \cdot 7)$ & $313(33 \cdot 1)$ & $120(7 \cdot 6)$ \\
\hline Head or neck & $58(12 \cdot 3)$ & $63(7 \cdot 2)$ & $21(2 \cdot 2)$ & $44 \quad(2 \cdot 8)$ \\
\hline Trunk & $89(18.9)$ & $413(47 \cdot 5)$ & $77 \quad(8 \cdot 1)$ & $262(16 \cdot 5)$ \\
\hline Arms & $16(3 \cdot 4)$ & $97(11 \cdot 1)$ & $109(11.5)$ & $215(13 \cdot 6)$ \\
\hline Legs & $49(10 \cdot 4)$ & $151(17 \cdot 4)$ & $248(26 \cdot 2)$ & $809(51 \cdot 1)$ \\
\hline Feet & $43(9 \cdot 1)$ & $32(3 \cdot 7)$ & $73(7 \cdot 7)$ & $63(4 \cdot 0)$ \\
\hline Hands & $7(1.5)$ & $7(0.8)$ & $23(2 \cdot 4)$ & $13(0 \cdot 8)$ \\
\hline Mucosal & $21(4 \cdot 5)$ & $12(1 \cdot 4)$ & $49(5 \cdot 2)$ & $23(1 \cdot 5)$ \\
\hline Subungual & $30(6 \cdot 4)$ & $20(2 \cdot 3)$ & $33(3.5)$ & $31 \quad(2 \cdot 0)$ \\
\hline Other & $4(0.8)$ & $8(0.9)$ & $1(0 \cdot 1)$ & $4(0 \cdot 3)$ \\
\hline Missing data & 5 & 8 & 7 & 11 \\
\hline Total & 471 & 870 & 947 & 1584 \\
\hline
\end{tabular}


tumours. The trunk was the second most common site in older men; in older women it was the leg. Acral, mucosal, and subungual melanomas were also more common in the older age group.

In most published series of all age groups the commonest reported histogenetic type is superficial spreading melanoma, usually accounting for $60-70 \%$ of lesions. Nodular melanomas usually account for 15 $20 \%$, lentigo maligna melanoma for $5-10 \%$, and acral or mucosal lesions for $2-5 \%$. Table III shows that in this series of patients aged 65 and over superficial spreading melanoma was also the most common histogenetic type ( $34 \%$ of melanomas), although the proportion was lower than in general series, while the proportion of other histogenetic types was increased. In the older age group nodular melanomas comprised $26 \%$, lentigo maligna melanomas $25 \%$, and acral or mucosal lesions $9 \%$. The steadily increasing incidence of melanoma over the decade of study was associated with a large increase in superficial spreading

TABLE III-Histogenetic type of melanoma

\begin{tabular}{|c|c|c|c|c|}
\hline & \multicolumn{2}{|c|}{ No $(\%)$ in men } & \multicolumn{2}{|c|}{ No $(\%)$ in women } \\
\hline & Age $\geqslant 65$ & Age $<65$ & Age $\geqslant 65$ & Age $<65$ \\
\hline Superficial spreading melanoma & $133(28.9)$ & $556(65 \cdot 0)$ & $335(36 \cdot 0)$ & $1103(70 \cdot 3)$ \\
\hline Nodular & $130(28 \cdot 2)$ & $191(22 \cdot 3)$ & $228(24 \cdot 5)$ & $283(18 \cdot 0)$ \\
\hline Lentigo maligna melanoma & $112(24 \cdot 3)$ & $44(5 \cdot 1)$ & $235(25 \cdot 2)$ & $76(4 \cdot 8)$ \\
\hline Acral or mucosal & $52(11 \cdot 3)$ & $32(3 \cdot 8)$ & $75(8 \cdot 1)$ & $63(4 \cdot 0)$ \\
\hline Other (including unclassifiable) & $34(7 \cdot 3)$ & $32(3.8)$ & $58 \quad(6 \cdot 2)$ & $45(2 \cdot 9)$ \\
\hline Missing data & 15 & 23 & 23 & 25 \\
\hline Total & 461 & 855 & 931 & 1570 \\
\hline
\end{tabular}

TABLE IV-Site of melanoma with Breslow thickness $\geqslant 3.5 \mathrm{~mm}$

\begin{tabular}{lrrrrrr}
\hline & \multicolumn{2}{c}{ No(\%) in men } & & \multicolumn{2}{c}{ No (\%) in women } \\
\cline { 2 - 3 } \cline { 6 - 7 } & Age $\geqslant 65$ & Age $<65$ & & Age $\geqslant 65$ & Age $<65$ \\
\hline Face & $45(24 \cdot 9)$ & $15(6 \cdot 8)$ & & $91(26 \cdot 4)$ & $21(9 \cdot 0)$ \\
Head or neck & $26(14 \cdot 3)$ & $21(9 \cdot 6)$ & & $7(2 \cdot 0)$ & $9(3 \cdot 8)$ \\
Trunk & $35(19 \cdot 3)$ & $95(43 \cdot 4)$ & & $37(10 \cdot 7)$ & $38(16 \cdot 2)$ \\
Arms & $4(2 \cdot 2)$ & $24(11 \cdot 0)$ & & $44(12 \cdot 8)$ & $26(11 \cdot 1)$ \\
Legs & $26(14 \cdot 4)$ & $39(17 \cdot 8)$ & & $80(23 \cdot 2)$ & $100(42 \cdot 7)$ \\
Feet & $22(12 \cdot 1)$ & $9(4 \cdot 1)$ & & $26(7 \cdot 6)$ & $16(6 \cdot 9)$ \\
Hands & $1(0 \cdot 6)$ & $4(1 \cdot 8)$ & & $15(4 \cdot 3)$ & $3(1 \cdot 3)$ \\
Mucosal & $5(2 \cdot 8)$ & $5(2 \cdot 3)$ & & $25(7 \cdot 2)$ & $10(4 \cdot 3)$ \\
Subungual & $17(9 \cdot 4)$ & $7(3 \cdot 2)$ & & $20(5 \cdot 8)$ & $11(4 \cdot 7)$ \\
\hline Total & 181 & 219 & & 345 & 234
\end{tabular}

TABLE V-Number (age adjusted percentage) of melanomas with Breslow thickness $\geqslant 1.5 \mathrm{~mm}$ before and after public education campaigns in Scotland

\begin{tabular}{|c|c|c|c|c|c|c|}
\hline \multirow[b]{2}{*}{ Age group } & \multicolumn{3}{|c|}{ Men } & \multicolumn{3}{|c|}{ Women } \\
\hline & Before & After & p Value & Before & After & p Value ${ }^{\star}$ \\
\hline$\geqslant 65$ & $131(70 \cdot 4)$ & $165(65 \cdot 1)$ & $>0.05$ & $307(71 \cdot 6)$ & $262(54 \cdot 3)$ & $<0.001$ \\
\hline$<65$ & $220(64.9)$ & $230(46 \cdot 0)$ & $<0.001$ & $343(50 \cdot 3)$ & $301(34 \cdot 7)$ & $<0.001$ \\
\hline
\end{tabular}

${ }^{\star}$ Derived from logistic regression analysis of Breslow thickness $(<1.5 \mathrm{~mm}$ or $\geqslant 1.5 \mathrm{~mm})$ before and after 1984 , adjusting for age, histogenetic type, anatomical site, and year of diagnosis.

TABLE VI - Five year survival for patients diagnosed between 1979 and 1984

\begin{tabular}{|c|c|c|c|c|c|c|}
\hline & \multicolumn{6}{|c|}{ Breslow thickness } \\
\hline & \multicolumn{2}{|c|}{$0-1.49 \mathrm{~mm}$} & \multicolumn{2}{|c|}{$1.5-3.49 \mathrm{~mm}$} & \multicolumn{2}{|c|}{$\geqslant 3.5 \mathrm{~mm}$} \\
\hline & Men & Women & Men & Women & Men & Women \\
\hline \multicolumn{7}{|l|}{ Patients aged 65 or over: } \\
\hline No & 55 & 123 & 45 & 119 & 86 & 188 \\
\hline No dead of melanoma & 9 & 9 & 18 & 31 & 48 & 79 \\
\hline No dead of other causes & 14 & 19 & 10 & 25 & 20 & 46 \\
\hline No alive with recurrence & 3 & 3 & 1 & 5 & 4 & 13 \\
\hline No alive and free of disease & 29 & 92 & 16 & 58 & 14 & 50 \\
\hline \multicolumn{7}{|l|}{5 Year actuarial survival: } \\
\hline $\begin{array}{l}\text { Overall for patients aged } 65 \text { or } \\
\text { over }(\%)\end{array}$ & 57 & 77 & 39 & 52 & 19 & 34 \\
\hline \multicolumn{7}{|l|}{ Specific for melanoma: } \\
\hline Patients aged 65 or over $(\%)$ & 80 & 92 & 55 & 71 & 32 & 53 \\
\hline Patients aged under $65(\%)$ & 87 & 97 & 65 & 81 & 41 & 55 \\
\hline
\end{tabular}
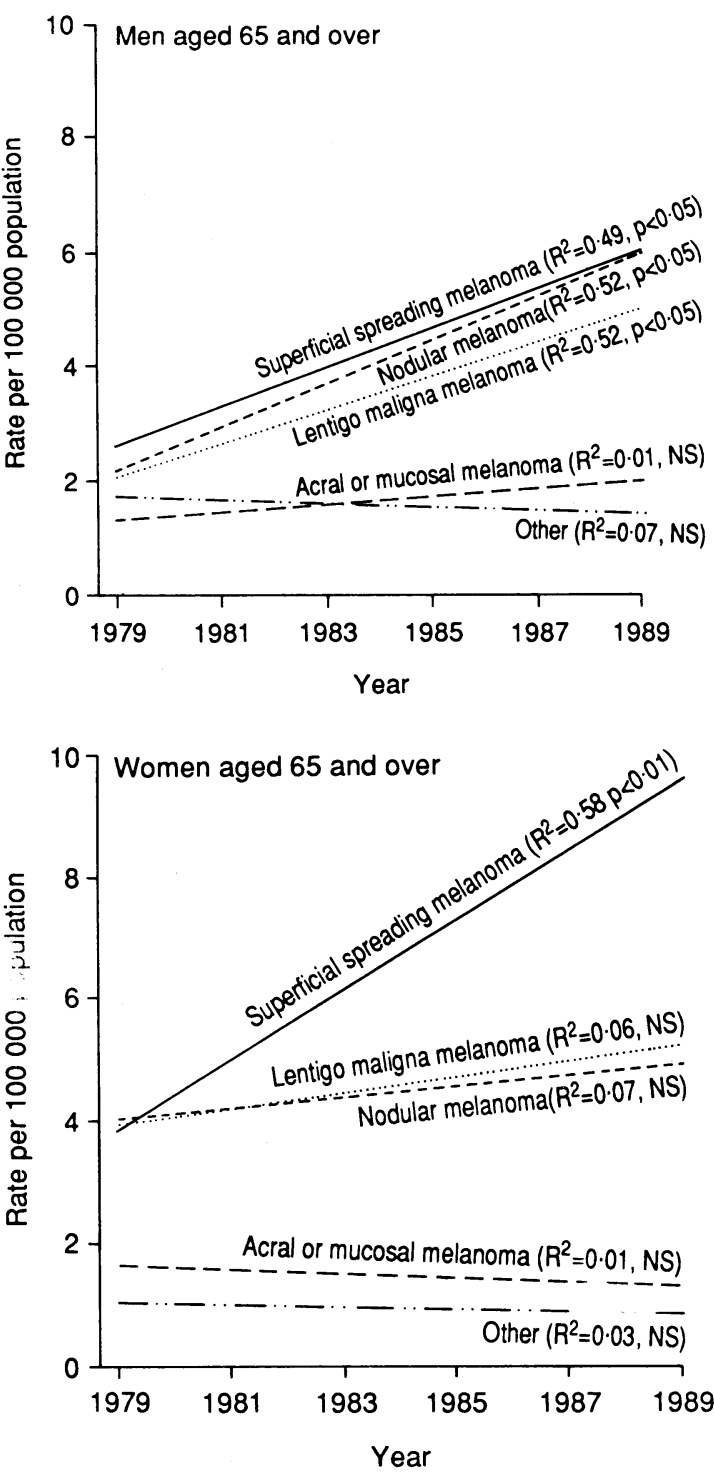

FIG 2-Changes in histogenetic type of melanoma in Scotland, 1979-89

melanomas in older women and a significant increase in superficial spreading melanoma, lentigo maligna melanoma, and nodular types in older men (fig 2). No significant increase in the incidence of acral or mucosal tumours was seen for either men or women over the period of study.

Tumour thickness measurement showed that 526 (37\%) patients aged 65 and over had melanomas that were $3.5 \mathrm{~mm}$ or thicker during the 11 year period. Of these, $169(32 \%)$ were found in the head and neck area (table IV). Thus over a third of melanomas in the older age group occurred in the head and neck region, and of these about a third fell into the worst thickness category.

The most important factor in prognosis for melanoma is tumour thickness. We looked at the proportion of melanomas with Breslow thicknesses of $1.5 \mathrm{~mm}$ or greater before and after the public education campaigns (table V). In both men and women under 65 there was a significant fall in the proportion of tumours $\geqslant 1.5 \mathrm{~mm}$ $(p<0.001)$. In men aged 65 and over the fall in the proportion of these tumours was not significant. In women aged 65 and over, although there was a significant fall in the proportion of melanomas $\geqslant 1.5 \mathrm{~mm}$ over the period of study, over half still had thicker tumours.

Five year survival data were available for 616 of the 656 older patients registered with melanoma between 1979 and 1984 (table VI). The five year survival rates specific for melanoma for tumour thicknesses of 0-1.49 
$\mathrm{mm}, 1 \cdot 5-3 \cdot 49 \mathrm{~mm}$, and $\geqslant 3.5 \mathrm{~mm}$ were $88 \%, 66 \%$, and $47 \%$ respectively. In each thickness group survival was better for women than for men. Overall, the five year survival specific for melanoma was $64 \%$ for the older age group, which is similar to the survival rate reported by other groups for older patients. ${ }^{5}$ For the younger age group overall five year survival specific for melanoma was $78 \%$. With Cox's proportional hazards model the Breslow thickness, ulceration, and sex were found to be the most important prognostic factors. Age above 65 years compared with under 65 was also found to be associated with a significantly poorer prognosis $(\mathrm{p}<0.01)$, independent of Breslow thickness, ulceration, sex, and histogenetic type.

\section{Discussion}

This study confirmed our impression that the pattern of presentation of malignant melanoma is different in elderly patients (65 and over). Several centres, including our own, have embarked on public education exercises aimed at all adults and encouraging early referral of thinner melanomas, which have a better prognosis. ${ }^{6}$ To date no specific message has been aimed at older patients, and our results would suggest that these public education campaigns have not yet reached the over 65 section of the Scottish population, who still have a disturbingly high proportion of thick tumours. A higher proportion of thick tumours in the older age group has been reported by North American groups ${ }^{78}$ and recently from Australia (P Hersey et al, second international symposium on epidemiology of malignant melanoma, Vancouver, 1991). Our figures strongly suggest that public education aimed specifically at older people is required. Education needs to be directed not only at elderly people but also at those who care for them. Campaigns should emphasise that in older people the incidence of melanoma is increasing, particularly in older men; the site most commonly affected in both sexes is the face; and if melanoma is identified early the outlook is still good.

Changing patterns of delivery of health care in the United Kingdom, with greater emphasis on health education and prevention in general practice, mean that this could be an appropriate time to enlist the help of family doctors in a specific programme aimed at informing elderly people about the features of early cutaneous melanoma. This will entail dermatologists offering a preparatory educational programme to general practitioners to help them differentiate true early melanoma from benign non-melanoma pigmented lesions. This programme should also be aimed at district nurses and others involved in the care of elderly patients.

1 Balch CM, Soong SJ, Shaw HM. A comparison of worldwide melanoma data In: Balch CM, Milton GW. Cutaneous melanoma. Philadelphia: Lippincott, In: B.

2 Breslow A. Thickness, cross sectional area and depth of invasion in the prognosis of cutaneous melanoma. Ann Surg 1970;172:902-8.

prognosis of cutaneous melanoma. Ann Surg 1970;172:902-8.
Cox DR. The analysis of binary data. London: Methuen, 1970.

3 Cox DR. The analysis of binary data. London: Methuen, 1970. Kournal of the American Statistical Association 1958;53:457-81.
forlan EL, Meier P. Non-parametric estimation from incomple

5 Shaw HM, McGovern VJ, Milton GW, Farago GA, McCarthy WH. Malignan melanoma: influence of site of lesion and age of patient in the female superiority in survival. Cancer 1980;46:2731-5.

6 Doherty VR, Mackie RM. Experience of a public education programme on early detection of cutaneous malignant melanoma. BMf 1988;297:388-91.

7 Rivers JK, Kelly MC, Kopf AW, Welkovich B, Bart RS. Age and malignan melanoma: comparison of variables in different age groups. $\mathcal{f}$ Am Acad Dermato 1989;21:717-22.

8 Cohen HJ, Cox E, Manton K, Woodbury M. Malignant melanoma in the elderly. F Clin Oncol 1987;5:100-6.

(Accepted 13 fanuary 1992)

\title{
Home based care and standard hospital care for patients with severe mental illness: a randomised controlled trial
}

\author{
M Muijen, I Marks, J Connolly, B Audini
}

\section{Abstract}

Objective-To compare the efficacy of home based care with standard hospital care in treating serious mental illness.

Design-Randomised controlled trial.

Setting-South Southwark, London.

Patients -189 patients aged 18-64 living in catchment area. 92 were randomised to home based care (daily living programme) and 97 to standard hospital care. At three months' follow up $\mathbf{6 8}$ home care and 60 hospital patients were evaluated.

Main outcome measures-Use of hospital beds, psychiatric diagnosis, social functioning, patients' and relatives' satisfaction, and activity of daily living programme staff.

Results - Home care reduced hospital stay by $80 \%$ (median stay six days in home care group, 53 days in hospital group) and did not increase the number of admissions compared with hospital care. On clinical and social outcome there was a non-significant trend in favour of home care, but both groups showed big improvements. On the global adjustment scale home care patients improved by 26.8 points and the hospital group by 21.6 points (difference $5 \cdot 2$; $95 \%$ confidence interval -1.5 to 12 ). Other rating scales showed similar trends. Home care patients required a wide range of support in areas such as housing, finance, and work. Only three patients dropped out from the programme.
Conclusions-Home based care may offer some slight advantages over hospital based care for patients with serious mental illness and their relatives. The care is intensive, but the low drop out rate suggests appreciation. Changes to traditional training for mental health workers are required.

\section{Introduction}

For about 40 years in most Western countries there has been a steady move away from treating patients with a serious mental illness in mental hospitals to caring for them in the community. ${ }^{12}$ In Britain this trend has been bolstered by official policy. ${ }^{3+}$ Initially, little research evidence was produced to support the advantages of community care, but in the past two decades several controlled studies outside Britain have compared home and inpatient care. ${ }^{56}$ The outcome measures used in the studies varied, but any significant differences consistently favoured the patients cared for at home with greater improvement in clinical symptoms and social functioning and in patients' and relatives' satisfaction. No study found inpatient care to be better on any variable. ${ }^{5}$ At the end of the studies the patients cared for at home still had many symptoms and much disability despite their relatively greater improvement. The importance of continuity of care was illustrated by the gradual loss of gains after withdrawal of home care, even after 14 months of home care. ${ }^{78}$
SE1 1LB.

BMf 1992;304:749-54 